\title{
Excitatory Actions of GABA in the Suprachiasmatic Nucleus
}

\author{
Hee Joo Choi, ${ }^{1 \star}$ C. Justin Lee, ${ }^{2 \star}$ Analyne Schroeder, ${ }^{3}$ Yoon Sik Kim, ${ }^{1}$ Seung Hoon Jung, ${ }^{1}$ Jeong Sook Kim, ${ }^{1}$ \\ Do Young Kim, ${ }^{1}$ Eun Ju Son, ${ }^{1}$ Hee Chul Han, ${ }^{1}$ Seung Kil Hong, ${ }^{1}$ Christopher S. Colwell, ${ }^{3}$ and Yang In Kim ${ }^{1}$ \\ ${ }^{1}$ Department of Physiology and Neuroscience Research Institute, Korea University College of Medicine, Seoul 136-705, Republic of Korea, ${ }^{2} \mathrm{Center}$ for \\ Neural Science, Korea Institute of Science and Technology, Seoul 136-791, Republic of Korea, and ${ }^{3}$ Department of Psychiatry and Biobehavioral Sciences, \\ University of California, Los Angeles, Los Angeles, California 90024
}

Neurons in the suprachiasmatic nucleus (SCN) are responsible for the generation of circadian oscillations, and understanding how these neurons communicate to form a functional circuit is a critical issue. The neurotransmitter GABA and its receptors are widely expressed in the SCN where they mediate cell-to-cell communication. Previous studies have raised the possibility that GABA can function as an excitatory transmitter in adult SCN neurons during the day, but this work is controversial. In the present study, we first tested the hypothesis that GABA can evoke excitatory responses during certain phases of the daily cycle by broadly sampling how SCN neurons respond to GABA using extracellular single-unit recording and gramicidin-perforated-patch recording techniques. We found that, although GABA inhibits most SCN neurons, some level of GABA-mediated excitation was present in both dorsal and ventral regions of the SCN, regardless of the time of day. These GABA-evoked excitatory responses were most common during the night in the dorsal SCN region. The $\mathrm{Na}^{+}-\mathrm{K}^{+}-2 \mathrm{Cl}^{-}$cotransporter (NKCC) inhibitor, bumetanide, prevented these excitatory responses. In individual neurons, the application of bumetanide was sufficient to change GABA-evoked excitation to inhibition. Calcium-imaging experiments also indicated that GABA-elicited calcium transients in SCN cells are highly dependent on the NKCC isoform 1 (NKCC1). Finally, Western blot analysis indicated that NKCC1 expression in the dorsal SCN is higher in the night. Together, this work indicates that GABA can play an excitatory role in communication between adult SCN neurons and that this excitation is critically dependent on NKCC1.

Key words: circadian rhythm; GABA; mouse; NKCC1; rat; suprachiasmatic nucleus

\section{Introduction}

The circadian clock orchestrating daily patterns of various physiological and behavioral processes in the mammal resides in the suprachiasmatic nucleus (SCN). The molecular machinery that drives circadian rhythmicity occurs in individual SCN neurons (Reppert and Weaver, 2001; Hastings and Herzog, 2004). This is not to imply that all SCN neurons are the same; in fact, a wide range of evidence is emerging for functionally distinct cell populations within the SCN (Hamada et al., 2001; Kuhlman et al., 2003; Lee et al., 2003). Anatomical evidence supports the broad division of the SCN into distinct ventral (core) and dorsal (shell) subdivisions (Abrahamson and Moore, 2001; Morin et al., 2006). Developing a mechanistic understanding of how SCN neurons communicate with each other within a subdivision or between

Received Sept. 20, 2007; revised April 11, 2008; accepted April 11, 2008.

This work was supported by grants from the Korea Research Foundation (KRF-2006-311-E00179) and Korea University (2006) (Y.I.K.) and National Institutes of Health Grant NS43169 (C.S.C.). H.J.C., Y.S.K., H.C.H., and Y.I.K. were supported by the Brain Korea 21 Project in 2006 and 2007.

*H.J.C. and C.J.L. contributed equally to this work.

Correspondence should be addressed to either of the following: Yang In Kim, Department of Physiology, Korea University College of Medicine, 126-1 Anam-dong 5-ga, Seoul 136-705, Republic of Korea, E-mail: yikim@korea.ac.kr; or Christopher S. Colwell, Department of Psychiatry and Biobehavioral Sciences, University of California, Los Angeles, 760 Westwood Plaza, Los Angeles, CA 90024, E-mail: ccolwell@mednet.ucla.edu.

D. Y. Kim's present address: Barrow Neurological Institute and St. Joseph's Hospital and Medical Center, Phoenix, AZ 85013.

E.J. Son's present address: Yong Dong Severance Hospital, Yonsei University College of Medicine, Seoul 135-720, Republic of Korea.

DOI:10.1523/JNEUROSCI.5750-07.2008

Copyright $\odot 2008$ Society for Neuroscience $\quad 0270-6474 / 08 / 285450-10 \$ 15.00 / 0$ the two subdivisions is a critical goal of this research area (Aton and Herzog, 2005).

Glutamic acid decarboxylase (GAD), the enzyme responsible for synthesizing GABA, is found in nearly all neurons of the SCN (Okamura et al., 1989; Moore and Speh, 1993), and both GABA and $\mathrm{GABA}_{\mathrm{B}}$ receptors are expressed in this structure (FrancoisBellan et al., 1989; Decavel and van den Pol, 1990). SCN neurons receive a tonic $\mathrm{GABA}_{\mathrm{A}}$ receptor-mediated synaptic input that, at least partly, originates within the $\mathrm{SCN}$ itself and peaks during the night (Kim and Dudek, 1992; Jiang et al., 1997; Strecker et al., 1997; Itri et al., 2004). Early work suggested that GABA could evoke excitatory responses during the day (Wagner et al., 1997), but the generality of this finding has been questioned by other laboratories (Gribkoff et al., 1999; De Jeu and Pennartz, 2002). Functionally, the exogenous application of GABA can synchronize the electrical activity of SCN neurons (Liu and Reppert, 2000; Shirakawa et al., 2000); however, GABAergic signaling does not appear to be required for cultured SCN neurons to remain synchronized (Aton et al., 2006). Intriguingly, there is evidence to suggest that GABA-mediated mechanisms are responsible for coupling ventral and dorsal cell populations in the SCN (Albus et al., 2005).

Here, we investigate the impact of GABA on the electrophysiological behaviors of SCN neurons using extracellular singleunit recording and gramicidin-perforated-patch recording techniques, which do not disrupt intracellular chloride concentration. Although exogenously applied GABA exerted mostly an 
inhibitory effect on the firing rate of SCN neurons, it produced excitation in a subset of neurons. In addition, whereas most neurons exhibited spontaneous IPSPs, some neurons showed $\mathrm{GABA}_{\mathrm{A}}$ receptor-mediated EPSPs. These excitatory events were most common in the dorsal region of the SCN during the night. Calcium-imaging data collected using $\mathrm{Na}^{+}-\mathrm{K}^{+}-2 \mathrm{Cl}^{-}$cotransporter (NKCC) blockers and NKCC1-deficient mice indicate that the excitatory effect of GABA is dependent on NKCC1. Finally, our Western blot measurements indicate that NKCC1 expression in the dorsal SCN peaks during the night. Overall, our findings indicate that GABA evokes excitatory responses in a subset of adult SCN neurons through a mechanism dependent on NKCC1.

\section{Materials and Methods}

Animals and housing. Male Sprague Dawley rats (100-380 g) purchased from Daehan Biolink or Charles River Laboratories International were used in this study. Also, male NKCC1 knock-out $\left(\mathrm{NKCC1}^{-/-}\right)$mice and their wild-type $\left(\mathrm{NKCC1}^{+/+}\right)$littermates $(30-40 \mathrm{~d}$ old) (Flagella et al., 1999) and C57BL/6 mice (age, 6-8 weeks) were used. The experimental procedures described below were approved by the Korea University College of Medicine Animal Research Policies Committee while conforming to National Institutes of Health guidelines. Before use, animals were housed in a temperature-controlled room $\left(22-24^{\circ} \mathrm{C}\right)$ with a $12 \mathrm{~h}$ light/ dark (LD) cycle. To evaluate diurnal variations in GABA-mediated responses, animals were killed $\sim 1 \mathrm{~h}$ before the beginning of the phase of interest. When taking animals from the dark portion of the LD cycle, an infrared viewer was used to avoid light exposure. Zeitgeber time (ZT) is used to describe the projected time of the circadian clock within the SCN based on the light cycle, with lights on defined as ZT 0.

Hypothalamic slice preparation. Brain slices were prepared as described previously (Kim et al., 2001, 2005). Animals were anesthetized with sodium pentobarbitone $(100 \mathrm{mg} / \mathrm{kg}$, i.p.) and the brain was quickly excised from the skull and submerged in ice-cold physiological saline [composed of (in mM) $124 \mathrm{NaCl}, 1.3 \mathrm{MgSO}_{4}, 3 \mathrm{KCl}, 1.25 \mathrm{NaH}_{2} \mathrm{PO}_{4}, 26 \mathrm{NaHCO}_{3}, 2.4$ $\mathrm{CaCl}_{2}$, and 10 glucose]. After chilling (1-2 $\left.\mathrm{min}\right)$, the brain was trimmed to a block containing the hypothalamus and optic nerves. Using a vibroslicer (World Precision Instruments), two parasagittal slices (400-500 $\mu \mathrm{m})$, each containing one optic nerve (3-5 mm length) and an SCN, were cut from the tissue block in ice-cold physiological saline. For experiments in which optic nerve stimulation was not needed, SCN slices $(400-500 \mu \mathrm{m})$ were cut in coronal orientation. The slices were kept in aerated $\left(95 \% \mathrm{O}_{2} / 5 \% \mathrm{CO}_{2}\right)$ physiological saline at room temperature (30-60 $\mathrm{min})$ before being transferred to an electrophysiological recording chamber.

Acute dissociation of SCN cells. Hypothalamic slices containing the SCN (300-350 $\mu \mathrm{m}$; coronal orientation) were prepared from postnatal day 30 (P30)-P40 rats or mice as described above. After being incubated in aerated $\left(95 \% \mathrm{O}_{2} / 5 \% \mathrm{CO}_{2}\right)$ physiological saline at room temperature (30-60 $\mathrm{min}$ ), the slices were transferred to HEPES-buffered saline [composed of (in mM) $124 \mathrm{NaCl}, 3 \mathrm{KCl}, 2.4 \mathrm{CaCl}_{2}, 10 \mathrm{HEPES}, 10$ glucose, and 35 sucrose] that contained $2 \mathrm{mg} / \mathrm{ml}$ protease (type XIV; Sigma-Aldrich). After being incubated further in this solution $\left(15 \mathrm{~min}, 37^{\circ} \mathrm{C}\right)$, the slices were rinsed (7-10 min) with protease-free HEPES-buffered saline. Next, the SCN was "punched out" for mechanical dissociation of cells with fire-polished glass pipettes. The dissociated cells were washed twice with HEPES-buffered saline and plated on poly-D-lysine-coated glass coverslips. The coverslips were placed in an incubator (30-40 min) before use.

Extracellular single-unit recording. Extracellular recordings from SCN slices were conducted as described previously (Kim et al., 2001, 2005). The slices were superfused continuously $(1-1.5 \mathrm{ml} / \mathrm{min})$ with warm physiological saline $\left(35^{\circ} \mathrm{C}\right.$, pH 7.4) aerated with $95 \% \mathrm{O}_{2} / 5 \% \mathrm{CO}_{2}$. Warm air $\left(35^{\circ} \mathrm{C}\right)$ humidified by $95 \% \mathrm{O}_{2} / 5 \% \mathrm{CO}_{2}$ was also continuously blown over the slice to further ensure adequate oxygenation of the cells in the tissue. After $\sim 1 \mathrm{~h}$ of equilibration of the slice in the recording chamber, extracellular single-unit recordings from the SCN were taken with recording electrodes. These micropipettes $(4-7 \mathrm{M} \Omega$ ) were pulled from borosilicate tubing (Sutter Instrument) and filled with $3 \mathrm{~m} \mathrm{NaCl}, \mathrm{pH}$ 7.4. The voltage signals from recording electrodes were fed serially into an Axoclamp-2B amplifier (Molecular Devices) and a differential amplifier (model AM 502; Tektronix) for amplification, AC coupling, and bandpass filtering $(100 \mathrm{~Hz}-1 \mathrm{kHz})$. The processed signals were digitized and sampled at $50 \mu$ s intervals (Digidata1320A, Axoscope 8.1; Molecular Devices). The criteria used to identify single units were consistent waveform and spike amplitude. Any recordings that were suspected to contain more than one unit were not included in the data pool. Also, the units having signal-to-noise ratios $<4$ were discarded. For the off-line data analyses, the rate histograms of single-unit activities (integrated in $1 \mathrm{~s}$ time bins) were constructed using custom-made software (Physics Department, Korea University, Seoul, Korea). This program allowed (1) independent setting of a threshold for spike detection in user-specified time segments, (2) visual inspection of detected events, (3) artifact rejection, and (4) rate-histogram generation based on detected spikes. The rate histograms were used to determine the effects of drugs on neuronal firing rates. A given drug was judged to exert an effect when the following conditions were met: (1) if the number of spikes registered in a given time bin after drug application was greater than the mean $+2 \mathrm{SD}$ (or smaller than the mean $-2 \mathrm{SD}$ ) of number of the spikes registered in each of the 30 time bins immediately before drug application, and (2) if this was a reproducible phenomenon.

Gramicidin-perforated-patch recording. Current-clamp recordings were obtained from neurons in SCN slices equilibrated for $>1 \mathrm{~h}$ in the recording chamber (Kim et al., 2005). Micropipettes (tip diameter, 1.0$1.5 \mu \mathrm{m} ; 3-5 \mathrm{M} \Omega$ ) pulled from borosilicate tubing (Sutter Instrument) and filled with gramicidin $(50 \mu \mathrm{g} / \mathrm{ml})$-containing internal solution [containing (in mM) $143 \mathrm{~K}$-gluconate, $2 \mathrm{KCl}, 10 \mathrm{HEPES}$, and $0.5 \mathrm{EGTA}, \mathrm{pH}$ 7.2-7.3] were used for recording. With these electrodes, it usually took $7-15 \mathrm{~min}$ after forming a seal to obtain a stable perforated configuration. Only those recordings having steady series resistances (range, 40-100 $\mathrm{M} \Omega$ ) and action potential amplitudes of $\geq 20 \mathrm{mV}$ (range, $20-50 \mathrm{mV}$, measured from spike threshold) were included in the data pool. In the cells recorded with the criteria above, postsynaptic potentials were clearly detectable and membrane potential changes by current injections were not limited within the physiological range because of their high input resistance. The voltage signals from SCN neurons recorded by using Axoclamp-2B amplifier (bandwidth filter set at $10 \mathrm{kHz}$ ) were digitized and sampled at $50 \mu$ s intervals (Digidata1320, pClamp 8.0; Molecular Devices).

Calcium imaging. Dissociated SCN cells coated on glass coverslips were loaded with fura-2 AM for calcium imaging. Coverslips were incubated (20 $\mathrm{min})$ in fura-2 AM $(5 \mu \mathrm{M})$-containing HEPES-buffered saline at room temperature and then rinsed with HEPES-buffered saline before being transferred to the calcium imaging chamber, which was superfused continuously $(1.5 \mathrm{ml} / \mathrm{min})$ with HEPES-buffered saline. Backgroundsubtracted intensity images at two excitation wavelengths (340 and 380 $\mathrm{nm}$ ) were acquired using an EM CCD camera (Andor Technology) and Axon Imaging Work Bench 5.1 image processing program (Indec Systems). $\left[\mathrm{Ca}^{2+}\right]_{i}$ was expressed as the ratio of the fura- 2 fluorescence intensities excited at 340 and $380 \mathrm{~nm}$.

Drug application. All of the drugs and chemicals used in this study were purchased from Sigma-Aldrich. The solutions of GABA, bicuculline methiodide $\left(\mathrm{GABA}_{\mathrm{A}}\right.$ receptor antagonist), tetrodotoxin, NMDA, and DL-2amino-5-phosphonovalerate (AP5; NMDA receptor antagonist) were prepared by dissolving these drugs in physiological or HEPES-buffered saline at appropriate concentrations, and the solutions of 6,7dinitroquinoxaline-2,3-dione (DNQX; AMPA/KA receptor antagonist), bumetanide (NKCC antagonist), furosemide [nonselective blocker for $\mathrm{NKCC}$ and $\mathrm{K}^{+}-\mathrm{Cl}^{-}$cotransporter (KCC)], picrotoxin $\left(\mathrm{GABA}_{\mathrm{A}}\right.$ receptor antagonist), and nimodipine (L-type $\mathrm{Ca}^{2+}$ channel blocker) were prepared by diluting their stock solutions with physiological or HEPESbuffered saline (stock solution solvents: dimethyl sulfoxide for DNQX, furosemide and bumetanide, and ethanol for picrotoxin and nimodipine; final concentrations of dimethyl sulfoxide and ethanol: 0.01-0.05\% and $0.002-0.1 \%$, respectively). These drug solutions were applied to SCN slices or dissociated SCN cells by a gravity-feed bath-perfusion system. In this system, drug solutions were kept in syringe reservoirs con- 
nected to a manifold with multiple inputs (Warner Instruments) and aerated continuously with $95 \% \mathrm{O}_{2} / 5 \% \mathrm{CO}_{2}$ or $100 \% \mathrm{O}_{2}$. The opening and closing of each reservoir were controlled by an electronically operated solenoid valve. The output of the manifold was connected to the recording chamber through a polyethylene tube that circulates in a water jacket $\left(35^{\circ} \mathrm{C}\right)$. This arrangement ensured that the drug solution was warmed before it reached the cells.

For examination of the effects of GABA and bicuculline on the single-unit activities of SCN neurons, the experiments were conducted with a standard drug application protocol (i.e., $30 \mathrm{~s}$ GABA and $30 \mathrm{~s}$ bicuculline applications with 2 min intervals). Usually, the test was repeated two to three times for each drug to see whether the observed effect was reproducible. To prevent the consequences of repeated drug applications for subsequent applications on other cells in the same tissue, we washed the slice with drug-free physiological saline for at least $10 \mathrm{~min}$ before testing the next cell.

Electrical stimulation of the optic nerve or a site near the SCN. To determine whether a given SCN neuron under investigation was retinorecipient, the optic nerve was stimulated with a custom-made suction electrode; constant current pulses (biphasic square-wave) of $0.1-0.7$ $\mathrm{mA}$ intensity and $0.5 \mathrm{~ms}$ duration were applied in $10 \mathrm{~s}$ intervals. The neuron was considered retinorecipient if EPSPs were evoked with a short, constant latency. In some experiments, the dorsolateral border of the SCN was stimulated with a twisted bipolar tungsten electrode to evoke postsynaptic potentials; constant current pulses (biphasic square wave; 0.1-0.2 mA, $0.5 \mathrm{~ms}$ ) were applied in 5 or $10 \mathrm{~s}$ intervals.

Western blot analysis. Brain slices containing SCN were prepared as described above. The dorsal and ventral SCN regions were surgically separated under a dissecting microscope. The peptide expression of the neurons in these surgically bisected halves was not measured, but the ventral half would be expected to contain more neurons expressing vasoactive intestinal peptide, whereas the dorsal half would be expected to contain more vasopressin expressing neurons (Morin et al., 2006). The tissue from three mice was pooled to form a single sample. The dissected tissue was then flash frozen in $500 \mu \mathrm{l}$ of ice-cold homogenization buffer ( $50 \mathrm{~mm}$ Tris$\mathrm{HCl}, 50 \mathrm{~mm} \mathrm{NaF}, 10 \mathrm{~mm}$ EGTA, $10 \mathrm{~mm}$ EDTA, $80 \mu \mathrm{M}$ sodium molybdate, $5 \mathrm{~mm}$ sodium pyrophosphate, $1 \mathrm{~mm}$ sodium orthovanadate, $0.01 \%$ Triton X-100, and 4 mm para-nitrophenylphosphate). The homogenization buffer also contained cocktails of protease inhibitors (Complete Protease Inhibitors; Roche Molecular Biochemicals) and protein phosphatase inhibitors (Protein Phosphatase Inhibitor Cocktails I and II; SigmaAldrich). The tissue was homogenized with an ultrasonic cell disruptor (three times, $5 \mathrm{~s}$ ). Immediately after homogenization, aliquots were removed for protein analysis, and equal amounts of denaturing protein loading buffer [0.5 м Tris- $\mathrm{HCl}, \mathrm{pH} 6.8,4.4 \%$ (w/v) SDS, $20 \%$ (v/v) glycerol, $2 \%$ 2-mercaptoethanol, and bromophenol blue] were added. These homogenates were kept on ice for $\sim 45$ min while protein concentrations were determined using a Bio-Rad Protein Assay Kit. Homogenates containing 20-30 $\mu \mathrm{g}$ of protein each were electrophoresed on 15\% SDS-PAGE gels, transferred to nitrocellulose membranes, and probed with primary anti-rat NKCC1 antiserum (1:1000) overnight (Alpha Diagnostic International). The membranes were incubated with horseradish peroxidase-conjugated anti-rabbit secondary IgG (1:1000), and protein signals were visualized by chemiluminescence (Immun-Star HRP detection kit; Bio-Rad). A phosphorimager was used for quantification and day/night comparisons were analyzed simultaneously, using identical settings. Protein bands were boxed, and the integrated intensity of all the pixels within that band was calculated above object average background levels of a box of the same size.
Percentage changes attributable to temporal variation were calculated relative to the optical density volume of the corresponding untreated protein bands within a single experiment.

Statistical analysis. Numerical data are expressed as the mean \pm SEM. Paired and unpaired $t$ tests were used for comparison of data sets. $\chi^{2}$ or Fisher's exact test was performed for comparison of frequency data. $p<$ 0.05 was considered significant.

\section{Results}

\section{GABA-mediated excitation of SCN neurons}

Previous work has raised the possibility that GABA may cause excitatory responses in adult SCN neurons (Wagner et al., 1997; De Jeu and Pennartz, 2002), although this observation has been questioned (Gribkoff et al., 1999). To determine whether GABA could increase the firing rate of SCN neurons, we measured the responses to GABA $(100 \mu \mathrm{M})$ and bicuculline $(30 \mu \mathrm{M})$ of a large sample of SCN neurons with single-unit recordings made throughout the daily cycle. Of 786 neurons tested for GABA, 141 showed no response and were not further analyzed. The remaining neurons $(n=645)$ exhibited one of three distinct patterns of responses to the application of GABA (Fig. 1). Most SCN neurons exhibited a simple decrease in firing rate $(n=467 ; 72 \%)$ (Fig. $1 A, B)$ in response to the application of GABA, as is typically seen in the adult nervous system. However, a second population of neurons responded to GABA with an increase in firing $(n=94$; $15 \%$ ) (Fig. 1C,D). Finally, the third population of SCN neurons exhibited a biphasic response to the application of GABA with an initial increase followed by a decrease in firing $(n=84 ; 13 \%)$ (Fig. $1 E, F)$. In all cases, these excitatory effects of GABA were prevented by the application of the $\mathrm{GABA}_{\mathrm{A}}$ receptor antagonist bicuculline $(30 \mu \mathrm{M})$ (Fig. $1 G, H)$. To determine whether tonic GABAergic synaptic transmission in the slice may be influencing excitability, we also measured the impact of application of bicuculline $(30 \mu \mathrm{M})$ alone on the firing rate of SCN neurons. Of 576 



Figure 2. $\quad A, B$, Proportions of rat $\mathrm{SCN}$ neurons showing various types of responses to GABA (100 $\mu \mathrm{m}, 30$ s pulse; $\boldsymbol{A}$ ) and bicuculline ( $30 \mu \mathrm{m}, 30 \mathrm{~s}$ pulse; $\boldsymbol{B}$ ) at different Zeitgeber times. The number of neurons examined at each time point is provided in the parentheses on top of each data set. Monophasic, Monophasic excitatory response; Biphasic, excitatory response followed by inhibitory response; Inhibition, inhibitory response; Excitation, excitatory response; NR, no response.

SCN neurons tested for a response to bicuculline, a large proportion $(n=259 ; 45 \%)$ showed no change in firing rate (Fig. $1 B, D, F)$. The remaining neurons $(n=317 ; 55 \%)$ exhibited an excitatory response $(n=256 ; 81 \%)$ (Fig. $1 A)$ and an inhibitory response $(n=61 ; 19 \%)$ (Fig. $1 C, E)$. Together, this data indicates that GABA inhibits most adult SCN neurons and that this transmitter acts to tonically decrease the firing rate of these neurons. However, in a subset of SCN neurons, application of GABA caused an increase in firing and the blockade of $\mathrm{GABA}_{\mathrm{A}}$ receptors decreased firing suggesting a tonic, ongoing GABA-mediated excitatory drive.

\section{GABA-mediated excitation is most common at night}

Previous work has raised the possibility that the effects of the application of GABA on SCN excitability may vary with the phase of the daily cycle (Wagner et al., 1997; De Jeu and Pennartz, 2002). To test possible circadian regulation of the impact of GABA, we measured the responses to the application of GABA $(100 \mu \mathrm{M})$ or bicuculline $(30 \mu \mathrm{M})$ of SCN neurons sampled across the day-night cycle $(n=12-59$ neurons/h). The respective pro-


Figure 3. GABAergic EPSPs in rat SCN neurons. $\boldsymbol{A}$, Reversible blockade of spontaneous EPSPS (asterisks) by bicuculline ( $30 \mu \mathrm{m})$; data from an SCN neuron recorded in the presence of DNQX $(20 \mu \mathrm{M})$ and DL-AP5 (100 $\mu \mathrm{M})$. B , Synaptic responses to optic nerve stimulation (results of 3 trials are shown) of an SCN neuron recorded before adding DNQX (20 $\mu \mathrm{M})$ and DL-AP5 (100 $\mu \mathrm{M})$ to the perfusion medium to isolate GABAergic EPSPs as shown in $\boldsymbol{A}$. This neuron responded to optic nerve stimulation (arrowhead) with EPSPs, which often triggered action potentials (diamonds). C, Day-night profile of the proportions of cells exhibiting spontaneous GABAergic EPSPs in three different neuronal groups in the SCN. The numerator and denominator in parentheses on top of each graph bar indicate the number of neurons that showed GABAergic EPSPS and the total number of cells examined, respectively. ND, Nonretinorecipient neurons in the dorsal region of the $\mathrm{SCN}$; RV, retinorecipient neurons in the ventral region of the $\mathrm{SCN}$; NV, nonretinorecipient neurons in the ventral region of the $\mathrm{SCN}$; NS, not significant. ${ }^{*} p<0.05$.

portions of neurons showing these excitatory or inhibitory responses to GABA at each phase of the daily cycle are summarized in Figure $2 A$, whereas the phase dependence of the response to bicuculline alone are shown in $B$. SCN neurons exhibited an excitatory response to GABA and an inhibitory response to bicuculline more frequently in the middle of the night (ZT 17-20) than at other phases of the daily cycle. During this night-time interval, approximately half of the total SCN neurons sampled increased their firing in response to GABA and decreased firing in response to bicuculline. Conversely, in the middle of the day (ZT 5-8), these types of excitatory responses to GABA and inhibitory 
responses to bicuculline were much less common $\left(\chi^{2}\right.$ test, $\left.p<0.001\right)$. These results suggest that the occurrence of GABAergic excitation is modulated in a circadian time-dependent manner.

\section{GABA-mediated excitation varies with the subregion of the SCN}

Next, we obtained gramicidin-perforatedpatch recordings of SCN neurons during the day (ZT 5-7) and night (ZT 17-20). We determined the $\mathrm{SCN}$ region (dorsal vs ventral) by visual placement and then characterized whether the neurons are retinorecipient by determining whether they respond to optic nerve stimulation. After this characterization, gramicidin-perforated-patch recordings were conducted in the presence of DNQX $(20 \mu \mathrm{M})$ and DL-AP5 $(100 \mu \mathrm{M})$ to block glutamate-mediated currents. Under these conditions, we recorded depolarizing (EPSPs), as well as hyperpolarizing (IPSPs), spontaneous synaptic events that were $\mathrm{GABA}_{\mathrm{A}}$ receptor mediated as they were completely blocked by bicuculline (30 $\mu \mathrm{M} ; n=7$ ) (Fig. $3 A$ ). The mean $( \pm \mathrm{SEM})$ resting membrane potentials of cells showing $\mathrm{GABA}_{\mathrm{A}}$ receptormediated EPSPs and IPSPs were $-56 \pm 1.2$ $\mathrm{mV}$ (range, -43 to $-68 \mathrm{mV} ; n=26$ ) and $-56 \pm 1.5 \mathrm{mV}$ (range, -45 to $-72 \mathrm{mV}$; $n=22$ ), respectively, and the mean reversal potentials of these synaptic events were $-45 \pm 3.0 \mathrm{mV}$ (range, -32 to $-53 \mathrm{mV} ; n=$ 9) and $-72 \pm 3.0 \mathrm{mV}$ (range, -55 to $-72 \mathrm{mV} ; n=13$ ), respectively. Many SCN neurons exhibited spontaneous $\mathrm{GABA}_{\mathrm{A}}$ receptor-mediated EPSPs (Fig. $3 A$ ). In the ventral region, spontaneous GABAergic EPSPs were detected in 10 of 89 (11\%) retinorecipient cells (Fig. 3B) and in 22 of 79 (28\%) nonretinorecipient cells, whereas in the remaining neurons GABAergic IPSPs were detected. In both the retinorecipient and nonretinorecipient cell groups, there was no significant day/night difference in the proportion of cells showing GABAergic EPSPs (Fig. $3 C$ ). In the dorsal SCN region, GABAergic EPSPs were detected in 25 of 91 nonretinorecipient cells (27\%) and IPSPs in the remaining neurons. A significantly higher proportion of neurons showed GABAergic EPSPs during the night than during the day (night, 38\%; day, $15 \%$ of cells; $p=0.025, \chi^{2}$ test) (Fig. $3 C$ ). Thus, although GABAmediated EPSPs occurs in all SCN regions, they are more common in dorsal SCN neurons during the night.

NKCC blocker bumetanide prevents GABA-evoked excitation One mechanism that can cause GABA-evoked depolarization is the activity of the chloride cotransporter NKCC1 (Russell, 2000). Therefore, we examined the effect of the NKCC antagonist bumetanide on the excitatory responses of SCN neurons to exogenously applied GABA (100 $\mu \mathrm{M} ; 5-30$ s pulses). The excitatory responses to these brief applications of GABA (either monophasic or biphasic) were observed in $\sim 23 \%$ ( $n=178$ of 786 ) of SCN neurons examined and blocked by bicuculline $(30 \mu \mathrm{M} ; n=13)$. Application of bumetanide suppressed the excitatory responses to GABA (Fig. $4 A, B$ ) by $86 \pm 5 \%$ at a concentration of $10 \mu \mathrm{M}$ $(n=14$ neurons $)$ and $99 \pm 1 \%$ at a concentration of $50 \mu \mathrm{M}(n=$ 12 neurons) (Fig. 4C). The peak effects occurred 5-15 min after application of the drug and could be partially reversed after wash (5-20 $\mathrm{min}, 56 \pm 12 \%$ recovery; $n=8$ ). Interestingly, among many of the neurons ( 9 of 12) that initially exhibited a monophasic excitatory response to GABA, the application of bumetanide caused a switch to GABA-evoked inhibition (Fig. 4 B). Among the neurons that initially exhibited a biphasic response to GABA, the application of bumetanide blocked the excitatory response while enhancing the GABA-induced inhibition (10 of 14 neurons) (Fig. 4C).

We sought to determine the role of NKCC in generating $\mathrm{GABA}_{\mathrm{A}}$ receptor-mediated EPSPs as measured by gramicidinperforated-patch recording (Fig. 5). As described above, these bicuculline-sensitive EPSPs (Fig. 3A) were isolated using a glutamate receptor antagonist mixture $(100 \mu \mathrm{M}$ DL-AP5 and $20 \mu \mathrm{M}$ DNQX). Bumetanide $(10 \mu \mathrm{M})$ decreased the amplitude of $\mathrm{GABA}_{\mathrm{A}}$ receptor-mediated spontaneous EPSPs [ $82 \pm 4 \%$ $(2.7 \pm 0.5 \mathrm{mV}$ to $0.5 \pm 0.2 \mathrm{mV}) ; n=8, p<0.001$, paired $t$ test] (Fig. $5 A$ ). The effects of bumetanide were maximal within 5-15 min after the commencement of its application and partially reversed during the wash (5-20 $\mathrm{min}, 20-50 \%$ recovery) (Fig. 5A). Bumetanide also exerted a profound effect on $\mathrm{GABA}_{\mathrm{A}}$ receptor-mediated EPSPs that were evoked by focal electrical stimulation of the dorsolateral border of the SCN. After bumetanide application $(10 \mu \mathrm{M} ; 10 \mathrm{~min})$, the reversal potential of the evoked EPSPs shifted significantly toward a hyperpolarized potential $(-44.3 \pm 0.8 \mathrm{mV}$ to $-55.6 \pm 1.8$ $\mathrm{mV} ; n=6$ neurons; $p<0.05$, paired $t$ test) (Fig. $5 B$ ), leading to a conversion of EPSPs to IPSPs in some neurons $(n=3)$ (Fig. $5 B 1)$. Together, this data suggests that the chloride cotransporter NKCC is required for GABA-evoked excitatory responses in SCN neurons. 

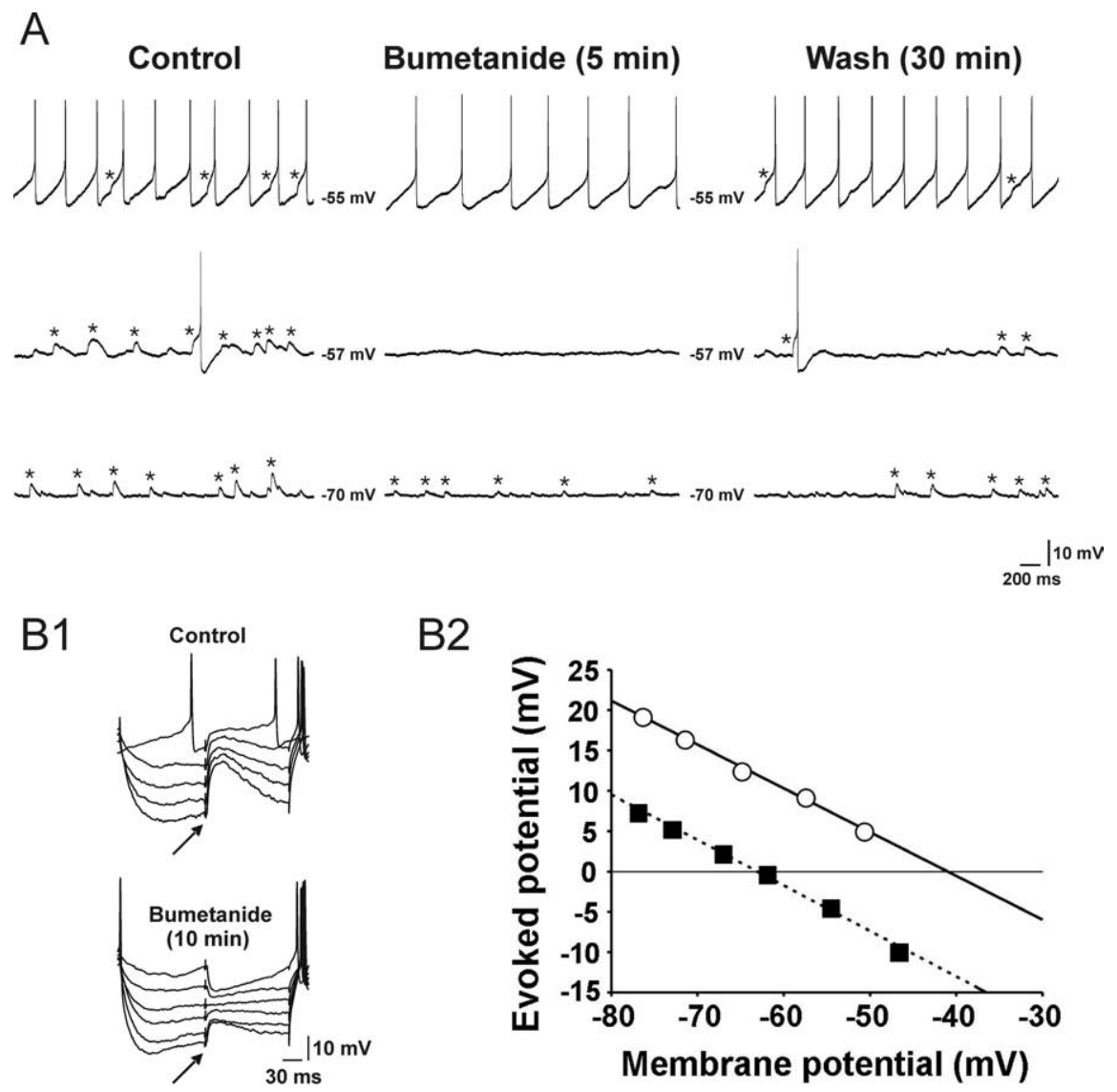

Figure 5. Effects of bumetanide (10 $\mu \mathrm{m})$ on EPSPs recorded in rat SCN neurons recorded with gramicidin-perforated-patch recording technique in the presence of DL-AP5 $(100 \mu \mathrm{m})$ and DNQX (20 $\mu \mathrm{M})$. A, Traces obtained at three different membrane potentials (i.e., $-55,-57$, and $-70 \mathrm{mV}$ ) are presented to help demonstrate the bumetanide effect more clearly. Asterisks denote spontaneous EPSPS. B1, Synaptic potentials evoked at various membrane potentials by focal electrical stimulation ( $\uparrow$ ) of the dorsolateral border of the SCN in the absence (top) and presence of bumetanide (bottom). The membrane potential was varied by injecting a series of current pulses (duration, $250 \mathrm{~ms}$; intensity, 0 to $-0.06 \mathrm{nA}$ ). This cell exhibited spontaneous EPSPs (data not shown), as did the cell in $\boldsymbol{A}$. B2, Estimation of the reversal potentials of the evoked synaptic responses shown in $\boldsymbol{B} 1$. The amplitudes of evoked responses are plotted against the baseline membrane potentials $(\bigcirc$, control; $\mathbf{\square}$, bumetanide). A linear regression was used to fit the data points. The intersections of the regression lines with the abscissa $(-41 \mathrm{and}-63 \mathrm{mV})$ were taken as the reversal potentials.

\section{GABA-induced calcium transients were blocked by NKCC inhibitors}

In many developing neurons including those from the SCN (Obrietan and van den Pol, 1997), application of GABA causes a membrane depolarization and subsequent $\mathrm{Ca}^{2+}$ transient. We used $\mathrm{Ca}^{2+}$-imaging techniques to determine whether we could record GABA-induced $\mathrm{Ca}^{2+}$ transients in acutely disassociated mature SCN cells ( $>$ P30). We found that application of GABA (100 $\mu \mathrm{M} ; 10$ or $20 \mathrm{~s}$ application) produced reliable $\mathrm{Ca}^{2+}$ increases (Fig. 6) in a subset of rat SCN cells ( $n=436$ of 1067 cells) sampled during both the projected day and night; the mean \pm SEM amplitude and duration (at half amplitude) of the $\mathrm{Ca}^{2+}$ responses evoked by $20 \mathrm{~s}$ GABA pulses were $0.60 \pm 0.05$ (F340/F380) and $29 \pm 1 \mathrm{~s}$, respectively $(n=117)$. These GABA-evoked $\mathrm{Ca}^{2+}$ responses were suppressed slightly by tetrodotoxin $(0.5 \mu \mathrm{M}$; F340/F380, $0.49 \pm 0.04$ to $0.36 \pm 0.04 ; n=27$ cells from 4 rats; $p<0.0001$, paired $t$ test) (Fig. 6A). However, they were completely blocked by application of a mixture of bicuculline and picrotoxin ( $50 \mu \mathrm{M}$ each; F340/F380, $0.55 \pm 0.05$ to $0.0 \pm 0.0 ; n=$ 31 cells from 4 rats) (Fig. $6 \mathrm{~B}$ ) as well as placing the cells in nominally zero calcium-containing bathing medium (F340/F380, $1.03 \pm 0.28$ to $0.0 \pm 0.0 ; n=20$ cells from 4 rats) (Fig. $6 C$ ).
Similarly, the GABA-evoked increases in intracellular calcium were prevented by application of nimodipine, an inhibitor of voltage-gated L-type $\mathrm{Ca}^{2+}$ channels $(2 \mu \mathrm{M}$; F340/F380, $0.65 \pm 0.09$ to $0.03 \pm 0.03 ; n=$ 17 cells from 4 rats) (Fig. $6 D$ ). The NKCC blockers bumetanide and furosemide also had inhibitory effects on the GABAevoked $\mathrm{Ca}^{2+}$ responses. Bumetanide at a concentration of $10 \mu \mathrm{M}$, a concentration selective for NKCC (Russell, 2000), blocked GABA-elicited $\mathrm{Ca}^{2+}$ rise in a reversible manner (Fig. $6 E, F$ ); the $\mathrm{Ca}^{2+}$ response decreased by $61 \pm 5 \%$ (F340/F380, $0.47 \pm 0.03$ to $0.21 \pm 0.03 ; n=65$ cells from 10 rats; $p<0.0001$, paired $t$ test) after 5 min bumetanide treatment and disappeared completely after $15 \mathrm{~min}$ treatment $(n=7)$, recovering to $97 \pm 7 \%(n=20)$ of the control after wash (20-30 min). Furosemide, an agent that blocks both NKCC and KCC, exerted weaker inhibitory effects on $\mathrm{GABA}$-evoked $\mathrm{Ca}^{2+}$ responses than did bumetanide; application ( $5 \mathrm{~min}$ ) of furosemide at concentrations of 30 and $300 \mu \mathrm{M}$ caused a reduction of the $\mathrm{Ca}^{2+}$ responses by $41 \pm 5 \%(\mathrm{~F} 340 / \mathrm{F} 380,0.95 \pm 0.10$ to $0.56 \pm 0.07 ; n=26$ cells from 2 rats; $p<$ 0.0001 , paired $t$ test) and $38 \pm 10 \%$ (F340/ F380, $0.92 \pm 0.11$ to $0.57 \pm 0.11 ; n=6$ cells from 2 rats; $p<0.02$, paired $t$ test), respectively (data not shown). These inhibitory effects of furosemide were reversible: the GABA-evoked $\mathrm{Ca}^{2+}$ responses were $92 \pm$ $4 \%(n=26)$ and $100 \pm 4 \%(n=6)$ of control after $20 \mathrm{~min}$ wash in cells tested with 30 and $300 \mu \mathrm{M}$ furosemide, respectively. Finally, we determined whether the loss of expression of NKCC1 would impact on GABA-evoked $\mathrm{Ca}^{2+}$ transients measured in the SCN. Compared with littermate controls, GABA-evoked $\mathrm{Ca}^{2+}$ transients were both less frequent $\left(\mathrm{NKCC}^{+/+}, 114\right.$ of 531 cells from 10 mice; $N K C C 1^{-/-}, 27$ of 494 cells from 6 mice; $\chi^{2}$ test, $p<0.001$ ) and lower amplitude $\left(\mathrm{NKCC}^{+/+}, 0.70 \pm 0.08 \mathrm{~F} 340 / \mathrm{F} 380, n=114\right.$ cells from 10 mice; $N \mathrm{NCC}^{-/-}, 0.32 \pm 0.03, n=27$ cells from 5 mice, $t$ test, $p<$ 0.02 ) in NKCC1-deficient mice. These infrequent, lowamplitude GABA-evoked $\mathrm{Ca}^{2+}$ transients observed in $\mathrm{NKCC1}^{-/-}$mice were insensitive to bumetanide, unlike GABAinduced $\mathrm{Ca}^{2+}$ responses in $\mathrm{NKCC1}^{+/+}$mice (Fig. 7), and must be caused by a mechanism other than NKCC1. Together, these results indicate that intracellular $\mathrm{Cl}^{-}$accumulation by NKCC in SCN neurons allows $\mathrm{Cl}^{-}$efflux during $\mathrm{GABA}_{\mathrm{A}}$ receptor activation, thus leading to the following sequence of events: membrane depolarization, voltage-gated L-type $\mathrm{Ca}^{2+}$ channel opening, influx of $\mathrm{Ca}^{2+}$, and intracellular $\mathrm{Ca}^{2+}$ rise.

\section{NKCC1 expression in dorsal SCN is higher during the night}

NKCC1 protein levels in the dorsal and ventral regions of the SCN were measured using Western-blot analysis (Fig. 8). Each sample was pooled from three mice $(\mathrm{C} 57 \mathrm{BL} / 6)$ and collected during the day (ZT 4) and night (ZT 16). Western blotting with a polyclonal antibody raised against the $\mathrm{C}$ terminus of the rat 
NKCC1 gave a clear band at the expected molecular weight $(\sim 160 \mathrm{kDa})$. This 160 $\mathrm{kDa}$ band was lost after preincubation of the NKCC1 primary antibody with a control peptide (data not shown). NKCC1 expression in the dorsal SCN was approximately twofold higher in the night compared with the day. In contrast, NKCC1 levels in samples from the ventral SCN region failed to show significant differences between the two time points. The Western blot experiment was repeated three times with the same results. Overall, the Western blot analysis indicates the presence of NKCC1 within the SCN and that the expression of NKCC1 is higher in the dorsal SCN region during the night.

\section{Discussion}

GABA can function as an excitatory transmitter within the SCN

In the present study, we showed that activation of $\mathrm{GABA}_{\mathrm{A}}$ receptors can facilitate action potential generation in a subset of mature SCN neurons. We also demonstrated that $\mathrm{GABA}_{\mathrm{A}}$ receptor-mediated EPSPs occur in these neurons. The reversal potential of the $\mathrm{GABA}_{\mathrm{A}}$ receptor-mediated potentials was depolarized relative to resting membrane potential. These synaptic events were sufficiently large to generate action potentials and, thus, were truly excitatory. GABA also evoked robust calcium transients within some SCN cells that were prevented by nimodipine, an L-type calcium channel blocker. This finding again indicates that GABA could be excitatory, because, in resting SCN neurons, greater depolarization is required to elicit L-type calcium channel current than sodiumdependent action potentials ( $\mathrm{H}$. Choi and Y. Kim, unpublished observations). Together, these results indicate that GABA, under some conditions, will have an excitatory role in cellular communication and regulation of firing rate within the $\mathrm{SCN}$.

The impact of GABA varies with a daily cycle and region of the $\mathrm{SCN}$

SCN neurons exhibit a daily rhythm in electrical activity and membrane conductance with peak electrical activity occurring during the subjective day (Schaap et al., 2003). Previous work has raised the possibility that the effects of GABA on SCN neurons may also vary with the circadian cycle (Wagner et al., 1997; De Jeu and Pennartz, 2002), but these findings have been proven controversial (Gribkoff et al., 1999, 2003). To help resolve these differences, we sampled the impact of GABA on large numbers of SCN neurons $(n=786)$ during all phases of the daily cycle. We found that the response to application of GABA is predominately inhibitory (59\% of neurons sampled). Dudek and colleagues (Gribkoff et al., 1999, 2003) have emphasized this aspect of GABA-mediated communication within the SCN. How-

$\mathrm{F}$

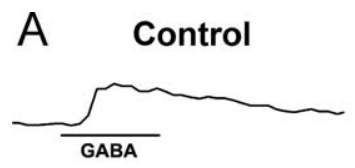

$\operatorname{TTX}(5 \mathrm{~min})$

BIC + PTX (3 min)



Calcium-free (5 $\mathrm{min})$

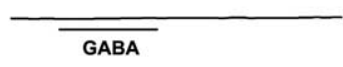

Nimodipine (1 $\mathrm{min})$
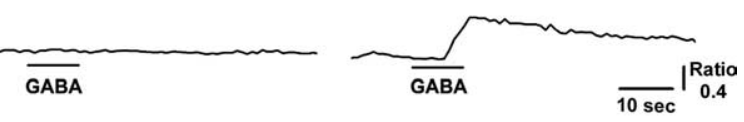

E Control

Bumetanide (5 min)
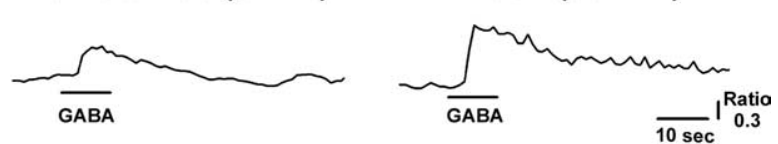


Figure 6. $\boldsymbol{A}-\boldsymbol{F}$, Effects of tetrodotoxin $(0.5 \mu \mathrm{m} ; \boldsymbol{A})$, bicuculline/picrotoxin (BIC + PTX, $50 \mu \mathrm{m}$ each; $\boldsymbol{B})$, nominally zero $\mathrm{Ca}^{2+}$-containing medium $(\boldsymbol{C})$, nimodipine $(2 \mu \mathrm{m} ; \boldsymbol{D})$, and bumetanide $(10 \mu \mathrm{m} ; \boldsymbol{E}, \boldsymbol{F})$ on intracellular $\mathrm{Ca}^{2+}$ rise elicited by GABA $(100 \mu \mathrm{M}) . \boldsymbol{A}-\boldsymbol{E}$, Data from five different rat SCN cells. $\boldsymbol{F}$, Plot of the mean ( \pm SEM) amplitude of GABA-evoked calcium transients obtained before, during, and after treatment with bumetanide ( $n=5$ rat SCN cells). GABA pulses ( $10 \mathrm{~s}$ duration) were delivered at 5 min intervals. Bumetanide application (solid line) was commenced immediately after obtaining the GABA-elicited calcium response at $0 \mathrm{~min}$ and terminated immediately after recording the calcium response at $5 \mathrm{~min}$. For each cell, the calcium responses were normalized to the response evoked $5 \mathrm{~min}$ before the application of bumetanide (i.e., at $-5 \mathrm{~min}$ ). Error bars indicate SEM.

ever, GABA-mediated inhibition is not exclusive, as a significant subpopulation of SCN neurons responded with excitation $(23 \%)$. Similarly, for a subset of SCN neurons (11\%), bicuculline decreases the firing rate consistent with tonic GABAergic excitation. We can confirm that GABA excites some SCN neurons during the day [as reported by Wagner et al. (1997)], but find that the proportion of cells that exhibit GABA-evoked excitation is much higher during the night, as reported by De Jeu and Pennartz (2002). Thus, during the day, when spontaneous firing is at a peak, ongoing GABAergic signaling within the SCN would limit the daily increase in firing rate driven by intrinsic membrane 


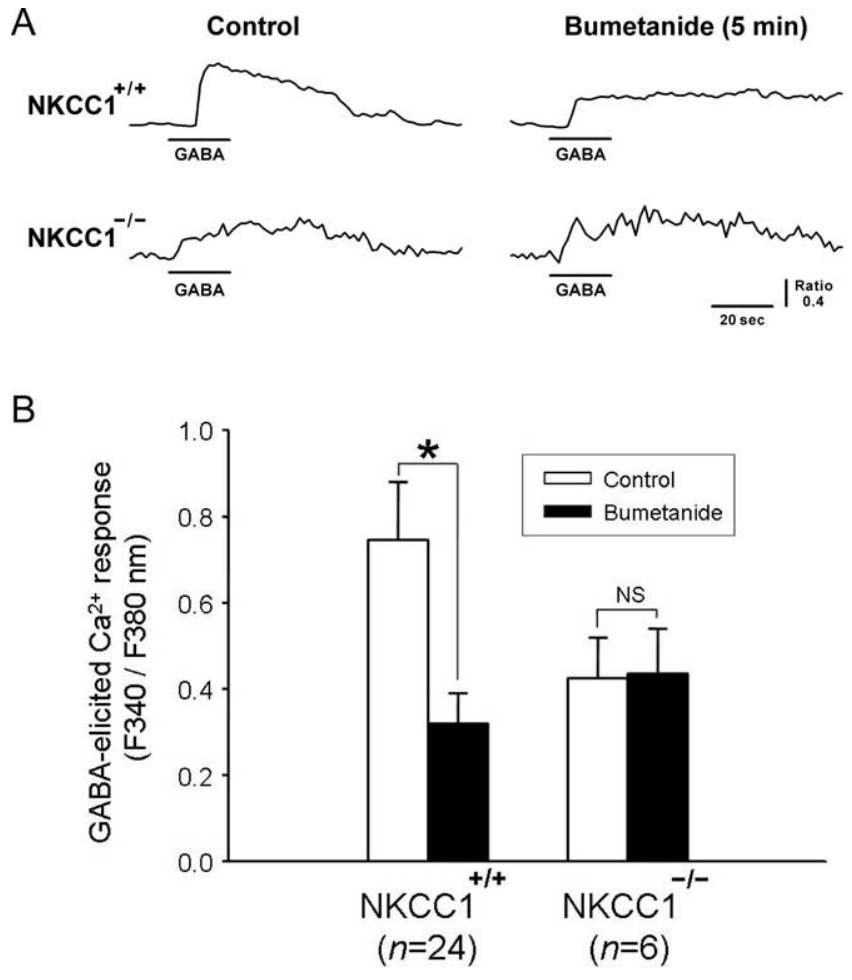

Figure 7. Comparison of SCN cells from NKCC1 knock-out $\left(\mathrm{NKCC}^{-/-}\right)$and wild-type $\left(\mathrm{NKCC} 1^{+/+}\right)$mice in terms of the sensitivity to bumetanide $(10 \mu \mathrm{M})$ of their GABA (100 $\left.\mu \mathrm{m}\right)$ elicited $\mathrm{Ca}^{2+}$ responses. NS, Not significant. ${ }^{*} p<0.05$. Error bars indicate SEM.

currents. During the night, these GABA-mediated currents provide excitatory drive for a subset of SCN neurons in the dorsal $\mathrm{SCN}$ region. Although the significance of this excitatory drive is not yet clear, neurons in this region exhibit robust rhythms in clock gene expression (Antle and Silver, 2005) that are likely to be influenced by this GABA-mediated excitation.

\section{GABA-induced calcium transients within SCN neurons}

In the developing nervous system, including the hypothalamus, it is well established that GABA has the ability to excite cells and increase $\left[\mathrm{Ca}^{2+}\right]_{\mathrm{i}}$ (Chen et al., 1996; Obrietan and van den Pol, 1997). In previous work, we have examined the effects of GABA on intracellular $\mathrm{Ca}^{2+}$ levels of SCN neurons in the acute brain slice preparation and found evidence for GABA-induced increases in $\mathrm{Ca}^{2+}$ in some cells (Colwell, 2001). The present study extended this previous work by examining the underlying mechanisms in mature rats and mice $(>\mathrm{P} 30)$. In other brain regions, GABA-evoked calcium transients are typically lost after P14 (Wang et al., 2005). We found evidence that $\mathrm{GABA}_{\mathrm{A}}$ receptor activation caused the following sequence of events: membrane depolarization, voltage-gated L-type $\mathrm{Ca}^{2+}$ channel opening, influx of $\mathrm{Ca}^{2+}$, and intracellular $\mathrm{Ca}^{2+}$ rise. Our results indicate that the initial depolarization is induced by the net efflux of $\mathrm{Cl}^{-}$ through $\mathrm{GABA}_{\mathrm{A}}$ receptors because of the positive shift of chloride equilibrium potential $\left(E_{\mathrm{Cl}^{-}}\right)$mediated by NKCC1. We estimated the average reversal potential of $\mathrm{GABA}_{\mathrm{A}}$ receptor-mediated $\mathrm{EP}$ SPs to be approximately $-45 \mathrm{mV}$, which corresponds to the lower tail of the current-voltage relationship of L-type $\mathrm{Ca}^{2+}$ channels. Although it requires a depolarization to approximately $-40 \mathrm{mV}$ to realize a pronounced activation of L-type $\mathrm{Ca}^{2+}$ channels, it is possible that the opening of a small number of L-type $\mathrm{Ca}^{2+}$ channels at below $-40 \mathrm{mV}$ (initiated by $\mathrm{GABA}_{\mathrm{A}}$ receptor-

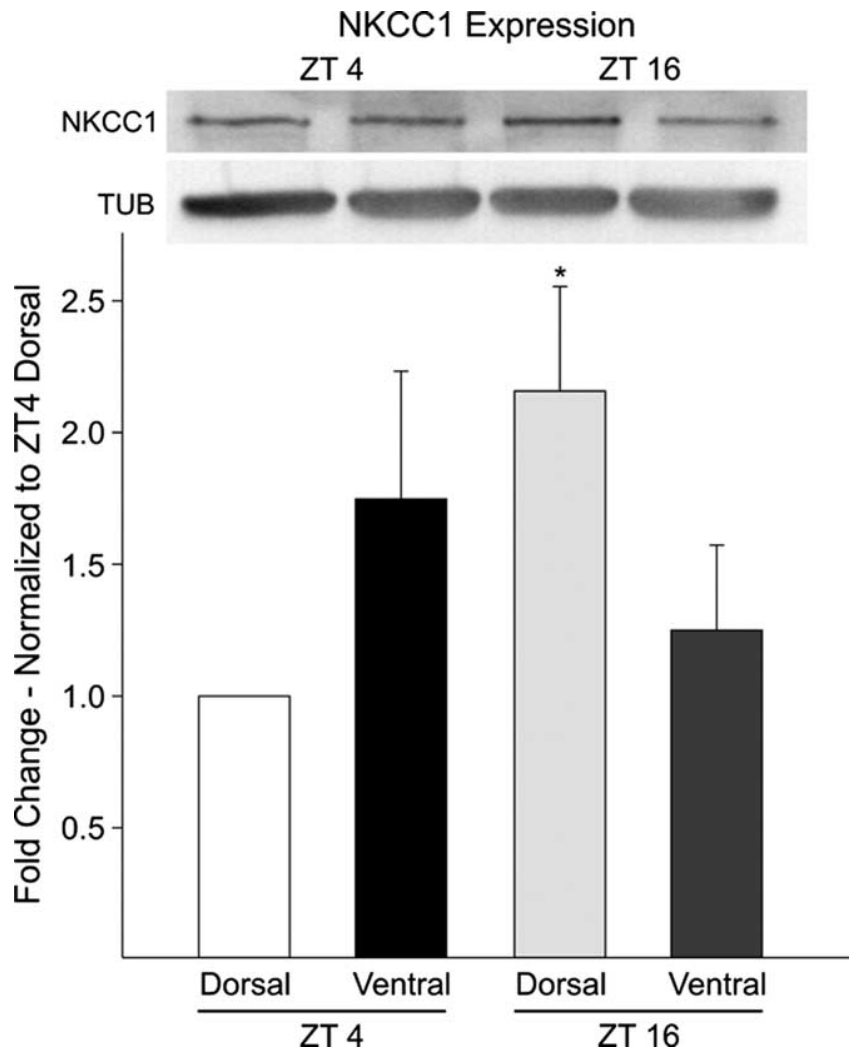

Figure 8. Western blot analysis of NKCC1 proteins from the dorsal and ventral regions of the mouse SCN taken at day (ZT 4) and night (ZT 16). Bottom, Histogram illustrating results from three independent experiments. NKCC1 levels were significantly $(p<0.05)$ higher in the night (ZT 16) in the dorsal region. In contrast, protein expression in the ventral region did not fluctuate. For each experiment, the values were normalized to samples collected from the dorsal SCN at ZT 4. Top, Anti-NKCC1 antibody recognized a high molecular weight band of $\sim 160 \mathrm{kDa}$ in size. NKCC1 levels were normalized to tubulin to control for loading. Error bars indicate SEM.

mediated depolarization) leads to a further depolarization and a regenerative opening of more L-type $\mathrm{Ca}^{2+}$ channels, because of its negative slope conductance. These regenerative depolarization and opening of L-type $\mathrm{Ca}^{2+}$ channels are sufficient to induce a significant $\mathrm{Ca}^{2+}$ influx and do not require TTX-sensitive sodium channel activation. The physiological meaning of this GABAevoked increase in intracellular $\mathrm{Ca}^{2+}$ levels remains to be determined.

\section{NKCC1 plays a crucial role in GABA-mediated excitation}

In a subset of SCN neurons, the reversal potentials for GABAergic postsynaptic potentials $\left(E_{\mathrm{GABA}}\right)$ are more depolarized than the resting potential and action potential threshold. Because $E_{\mathrm{GABA}}$ is mostly set by the $E_{\mathrm{Cl}^{-}}$, this indicates that the chloride levels are differentially regulated in these neurons. In the developing nervous system, changes in the expression of a family of cationchloride cotransporters are thought to be responsible for agerelated changes in the $E_{\mathrm{Cl}^{-}}$. NKCC1 raises intracellular chloride levels and thus contributes to a more depolarized $E_{\mathrm{Cl}^{-}}$. The effects of NKCC1 are balanced by KCC isoform 2 (KCC2), which normally lowers intracellular chloride levels. Several studies have suggested that the upregulation of KCC2 and the downregulation of NKCC1 are responsible for the developmental switch between GABA-evoked depolarization and hyperpolarization (Plotkin et al., 1997; Rivera et al., 1999; Yamada et al., 2004). A previous study found that KCC2 is highly expressed in the ventral SCN in association with neurons expressing vasoactive intestinal peptide 
and gastrin-releasing peptide (Belenky et al., 2008). The high levels of this chloride extrusion cotransporter in these ventral SCN neurons compliments the present finding that GABAmediated excitation is less common in this region.

Our data indicate that the continued expression of NKCC1 in the mature $\mathrm{SCN}$ is responsible for GABA-evoked excitation in SCN neurons. The pharmacological blockade of this cotransporter with bumetanide $(10 \mu \mathrm{M})$ (Russell, 2000) mostly prevented GABA-evoked excitation and GABA-evoked $\mathrm{Ca}^{2+}$ transients. Moreover, these $\mathrm{Ca}^{2+}$ transients were greatly reduced in mice deficient in NKCC1. Interestingly, in most $(>70 \%)$ of the SCN neurons investigated, the blockade of GABAergic excitation by bumetanide revealed a latent inhibition or isolated the inhibitory component of biphasic responses that was sensitive to bicuculline. Furthermore, in many SCN neurons, bumetanide converted GABAergic EPSPs into IPSPs. These findings are consistent with the hypothesis that two active chloride transport mechanisms operate in the same SCN neuron: one that replenishes the cell with chloride after chloride depletion and the other that removes chloride after chloride loading (Wagner et al., 2001).

Finally, our Western blot measurements indicated that NKCC1 is expressed in the SCN (Kanaka et al., 2001). Interestingly, the expression of NKCC1 in the dorsal SCN region was higher during the night than during the day. This raises the possibility that transcriptional/translational regulation of this cotransporter may underlie the day/night variation in GABAevoked excitation. Alternatively, phosphorylation has also been shown to regulate NKCC1 activity (Gagnon et al., 2007) and this type of posttranslational regulation could also be responsible for a daily increase in $\mathrm{NKCC} 1$ activity and subsequent GABA-driven excitation. The lack of KCC2 in dorsal SCN neurons (Belenky et al., 2008) could also serve to increase the frequency of GABAmediated excitation in this region.

\section{Functional significance of GABAergic excitation}

The excitatory actions of GABA described here are likely to be physiologically relevant in vivo, as our data clearly demonstrate that in a subset of SCN neurons the $E_{\mathrm{GABA}}$ is above the threshold for firing action potentials. Although the predominant effect of GABA-mediated signaling within the SCN would be inhibition, it can change to excitation in a way that is actively regulated by chloride transporters. Our data suggest that in SCN neurons chloride homeostasis is activity regulated by the balance in the activity of NKCC1 and, perhaps, KCC2 transporters. This GABAmediated signaling may sculpt, but does not appear to drive the rhythms in firing rate in SCN neurons. For example, a previous analysis of the role of GABA in SCN neurons in culture found that blocking GABA receptors alters the firing rate and precision of the neural activity rhythms but does not impair synchrony or rhythmicity of the population (Aton et al., 2006). However, previous work has also shown that exogenously applied GABA can phase shift the rhythms in electrical activity (Tominaga et al., 1994; Shirakawa et al., 2000) and can synchronize the population of cellular oscillators in culture (Liu and Reppert, 2000). The GABAergic excitation described in the present study is likely to have a robust impact on how dorsal SCN neurons respond to afferent input. Interestingly, GABA plays a role in the synchronization of the dorsal and ventral regions of the SCN (Albus et al., 2005). Together, these results suggest that GABAergic signaling within the SCN has an excitatory component whose role in the regulation of coupling and control of excitability within the SCN circuit deserves further analysis.

\section{References}

Abrahamson EE, Moore RY (2001) Suprachiasmatic nucleus in the mouse: retinal innervation, intrinsic organization and efferent projections. Brain Res 916:172-191.

Albus H, Vansteensel MJ, Michel S, Block GD, Meijer JH (2005) A GABAergic mechanism is necessary for coupling dissociable ventral and dorsal regional oscillators within the circadian clock. Curr Biol 15:886-893.

Antle MC, Silver R (2005) Orchestrating time: arrangements of the brain circadian clock. Trends Neurosci 28:145-151.

Aton SJ, Herzog ED (2005) Come together, right. . . now: synchronization of rhythms in a mammalian circadian clock. Neuron 48:531-534.

Aton SJ, Huettner JE, Straume M, Herzog ED (2006) GABA and Gi/o differentially control circadian rhythms and synchrony in clock neurons. Proc Natl Acad Sci USA 103:19188-19193.

Belenky MA, Yarom Y, Pickard GE (2008) Heterogeneous expression of $\gamma$-aminobutyric acid and $\gamma$-aminobutyric acid-associated receptors and transporters in the rat suprachiasmatic nucleus. J Comp Neurol 506:708-732.

Chen G, Trombley PQ, van den Pol AN (1996) Excitatory actions of GABA in developing rat hypothalamic neurones. J Physiol (Lond) 494:451-464.

Colwell CS (2001) NMDA-evoked calcium transients and currents in the suprachiasmatic nucleus: gating by the circadian system. Eur J Neurosci 13:1420-1428.

Decavel C, van den Pol AN (1990) GABA: a dominant neurotransmitter in the hypothalamus. J Comp Neurol 302:1019-1037.

De Jeu M, Pennartz C (2002) Circadian modulation of GABA function in the rat suprachiasmatic nucleus: excitatory effects during the night phase. J Neurophysiol 87:834-844.

Flagella M, Clarke LL, Miller ML, Erway LC, Giannella RA, Andringa A, Gawenis LR, Kramer J, Duffy JJ, Doetschman T, Lorenz JN, Yamoah EN, Cardell EL, Shull GE (1999) Mice lacking the basolateral Na-K-2Cl cotransporter have impaired epithelial chloride secretion and are profoundly deaf. J Biol Chem 274:26946-26955.

Francois-Bellan AM, Segu L, Hery M (1989) Regulation by estradiol of $\mathrm{GABA}_{\mathrm{A}}$ and $\mathrm{GABA}_{\mathrm{B}}$ binding sites in the diencephalon of the rat: an autoradiographic study. Brain Res 503:144-147.

Gagnon KB, England R, Delpire E (2007) A single binding motif is required for SPAK activation of the Na-K-2Cl cotransporter. Cell Physiol Biochem 20:131-142.

Gribkoff VK, Pieschl RL, Wisialowski TA, Park WK, Strecker GJ, de Jeu MT, Pennartz CM, Dudek FE (1999) A reexamination of the role of GABA in the mammalian suprachiasmatic nucleus. J Biol Rhythms 14:126-130.

Gribkoff VK, Pieschl RL, Dudek FE (2003) GABA receptor-mediated inhibition of neuronal activity in rat SCN in vitro: pharmacology and influence of circadian phase. J Neurophysiol 90:1438-1448.

Hamada T, LeSauter J, Venuti JM, Silver R (2001) Expression of Period genes: rhythmic and nonrhythmic compartments of the suprachiasmatic nucleus pacemaker. J Neurosci 21:7742-7750.

Hastings MH, Herzog ED (2004) Clock genes, oscillators, and cellular networks in the suprachiasmatic nuclei. J Biol Rhythms 19:400-413.

Itri J, Michel S, Waschek JA, Colwell CS (2004) Circadian rhythm in inhibitory synaptic transmission in the mouse suprachiasmatic nucleus. J Neurophysiol 92:311-319.

Jiang ZG, Yang Y, Liu ZP, Allen CN (1997) Membrane properties and synaptic inputs of suprachiasmatic nucleus neurons in rat brain slices. J Physiol (Lond) 499:141-159.

Kanaka C, Ohno K, Okabe A, Kuriyama K, Itoh T, Fukuda A, Sato K (2001) The differential expression patterns of messenger RNAs encoding $\mathrm{K}-\mathrm{Cl}$ cotransporters $(\mathrm{KCC} 1,2)$ and $\mathrm{Na}-\mathrm{K}-2 \mathrm{Cl}$ cotransporter $(\mathrm{NKCC} 1)$ in the rat nervous system. Neuroscience 104:933-946.

Kim DY, Kang HC, Shin HC, Lee KJ, Yoon YW, Han HC, Na HS, Hong SK, Kim YI (2001) Substance p plays a critical role in photic resetting of the circadian pacemaker in the rat hypothalamus. J Neurosci 21:4026-4031.

Kim DY, Choi HJ, Kim JS, Kim YS, Jeong DU, Shin HC, Kim MJ, Han HC, Hong SK, Kim YI (2005) Voltage-gated calcium channels play crucial roles in the glutamate-induced phase shifts of the rat suprachiasmatic circadian clock. Eur J Neurosci 21:1215-1222.

Kim YI, Dudek FE (1992) Intracellular electrophysiological study of suprachiasmatic nucleus neurons in rodents: inhibitory synaptic mechanisms. J Physiol (Lond) 458:247-260.

Kuhlman SJ, Silver R, LeSauter J, Bult-Ito A, McMahon DG (2003) Phase 
resetting light pulses induce Per1 and persistent spike activity in a subpopulation of biological clock neurons. J Neurosci 23:1441-1450.

Lee HS, Nelms JL, Nguyen M, Silver R, Lehman MN (2003) The eye is necessary for a circadian rhythm in the suprachiasmatic nucleus. Nat Neurosci 6:111-112.

Liu C, Reppert SM (2000) GABA synchronizes clock cells within the suprachiasmatic circadian clock. Neuron 25:123-128.

Moore RY, Speh JC (1993) GABA is the principal neurotransmitter of the circadian system. Neurosci Lett 150:112-116.

Morin LP, Shivers KY, Blanchard JH, Muscat L (2006) Complex organization of mouse and rat suprachiasmatic nucleus. Neuroscience 137:1285-1297.

Obrietan K, van den Pol AN (1997) GABA activity mediating cytosolic $\mathrm{Ca}^{2+}$ rises in developing neurons is modulated by cAMP-dependent signal transduction. J Neurosci 17:4785-4799.

Okamura H, Berod A, Julien JF, Geffard M, Kitahama K, Mallet J, Bobillier P (1989) Demonstration of GABAergic cell bodies in the suprachiasmatic nucleus: in situ hybridization of glutamic acid decarboxylase (GAD) mRNA and immunocytochemistry of GAD and GABA. Neurosci Lett 102:131-136.

Plotkin MD, Snyder EY, Hebert SC, Delpire E (1997) Expression of the $\mathrm{Na}-\mathrm{K}-2 \mathrm{Cl}$ cotransporter is developmentally regulated in postnatal rat brains: a possible mechanism underlying GABA's excitatory role in immature brain. J Neurobiol 33:781-795.

Reppert SM, Weaver DR (2001) Molecular analysis of mammalian circadian rhythms. Annu Rev Physiol 63:647-676.

Rivera C, Voipio J, Payne JA, Ruusuvuori E, Lahtinen H, Lamsa K, Pirvola U, Saarma M, Kaila K (1999) The $\mathrm{K}^{+} / \mathrm{Cl} \boldsymbol{\alpha}$ co-transporter KCC2 renders
GABA hyperpolarizing during neuronal maturation. Nature 397:251-255.

Russell JM (2000) Sodium-potassium-chloride cotransport. Physiol Rev $80: 211-276$.

Schaap J, Pennartz CM, Meijer JH (2003) Electrophysiology of the circadian pacemaker in mammals. Chronobiol Int 20:171-188.

Shirakawa T, Honma S, Katsuno Y, Oguchi H, Honma KI (2000) Synchronization of circadian firing rhythms in cultured rat suprachiasmatic neurons. Eur J Neurosci 12:2833-2838.

Strecker GJ, Wuarin JP, Dudek FE (1997) GABA $_{\mathrm{A}}$-mediated local synaptic pathways connect neurons in the rat suprachiasmatic nucleus. J Neurophysiol 78:2217-2220.

Tominaga K, Shibata S, Hamada T, Watanabe S (1994) $\mathrm{GABA}_{\mathrm{A}}$ receptor agonist muscimol can reset the phase of neural activity rhythm in the rat suprachiasmatic nucleus in vitro. Neurosci Lett 166:81-84.

Wagner S, Castel M, Gainer H, Yarom Y (1997) GABA in the mammalian suprachiasmatic nucleus and its role in diurnal rhythmicity. Nature 387:598-603.

Wagner S, Sagiv N, Yarom Y (2001) GABA-induced current and circadian regulation of chloride in neurons of the rat suprachiasmatic nucleus. J Physiol (Lond) 537:853-869.

Wang C, Ohno K, Furukawa T, Ueki T, Ikeda M, Fukuda A, Sato K (2005) Differential expression of KCC2 accounts for the differential GABA responses between relay and intrinsic neurons in the early postnatal rat olfactory bulb. Eur J Neurosci 21:1449-1455.

Yamada J, Okabe A, Toyoda H, Kilb W, Luhmann HJ, Fukuda A (2004) $\mathrm{Cl}^{-}$ uptake promoting depolarizing GABA actions in immature rat neocortical neurons is mediated by NKCC1. J Physiol (Lond) 557:829-841. 